\title{
Revendo bipartidarismos no contexto da teoria clássica do cinema: formalismo e realismo, identificação e essencialismo
}

\author{
Reviewing bipartisan systems in the context of \\ classical film theory: formalism and realism, \\ identification and essentialism
}

\author{
A LFREDO SUPPIA * \\ Universidade Estadual de Campinas, Departamento de Cinema. Campinas - SP, Brasil
}

\section{RESUMO}

O objetivo deste artigo é investigar aspectos da teoria clássica do cinema, com especial atenção aos primórdios do pensamento cinematográfico, visando ao esclarecimento de algumas controvérsias e o aprofundamento de determinados debates, os quais, ainda hoje, não parecem totalmente superados. Portanto, dois aspectos serão investigados: a oscilação entre aproximação e afastamento do cinema com relação às demais manifestações artísticas e a abordagem bipartidária da história da teoria do cinema, organizada em torno de dois eixos fundamentais, o formalista e o realista.

Palavras-chave: Teoria do cinema, história do cinema, Ricciotto Canudo, formalismo, realismo

\begin{abstract}
The objective of this paper is to to investigate the classical film theory, with special attention to the beginnings of film thinking, aiming to clarify some controversies and deepen certain debates, which, even today, do not seem to be fully overcome. Therefore, two aspects will be investigated: the oscillation between approach and retraction of the cinema in relation to other art forms and the bipartisan approach to the history of film theory, arranged around two main axes, the formalistic and realistic.
\end{abstract}

Keywords: Film theory, film history, Ricciotto Canudo, formalism, realism 
$\mathrm{P}$ RETENDO TRATAR DE dois problemas ou controvérsias emergentes nos primeiros desenvolvimentos da teoria do cinema, nas duas primeiras décadas do século $\mathrm{XX}$, os quais se prolongam até aproximadamente a metade do mesmo século - eventualmente persistindo até hoje.

A primeira controvérsia diz respeito a uma oscilação no bojo das discussões e da defesa do cinema enquanto forma legítima de arte. Essa oscilação se dá entre dois polos, aos quais darei os nomes de identificação e essencialismo. Chamo de identificação a manobra de reivindicação do status de arte para o cinema por meio de aproximações deste com formas de arte já consagradas: a pintura, a literatura, a música e o teatro. Identificação aqui não tem relação alguma com o conceito consagrado nos estudos de cinema de corte psicanalítico, o qual diz respeito a processos de identificação (primários ou secundários) do espectador com personagens de ficção, ou com o próprio dispositivo (Baudry, 1986: 286-298). Por essencialismo, entendo a tentativa de isolamento do específico cinematográfico, daquilo que diferencia o cinema das demais formas de arte. Essa oscilação não é trivial e, por vezes, dá margem a contradições num único texto ou discurso. Na falta de termos mais precisos, identificação e essencialismo pagam tributo, neste estudo, à longa tradição do paragone (“comparação", em italiano), método que confronta diferentes formas de arte, geralmente conduzido por um artista consagrado, no sentido de determinar alguma supremacia. Exemplos de paragone podem ser encontrados no Aretino (1557), de Ludovico Dolce, no Trattato della Pittura (c. 1500), de Leonardo Da Vinci, ou no Laocoonte (1998), de Gotthold Ephraim Lessing. Conforme será possível observar nas páginas seguintes, o paragone reaparece no pensamento de alguns dos primeiros e mais influentes críticos e teóricos do cinema no século XX, como Riciotto Canudo ou Rudolf Arnheim.

O segundo problema, que está relacionado ao primeiro, diz respeito à eventual cisão no pensamento cinematográfico entre duas correntes: o formalismo e o realismo. É comum o entendimento histórico do pensamento cinematográfico identificar o formalismo e o realismo como dois vetores ao redor dos quais se aglutinam um variado número de críticos, teóricos e/ou cineastas. Pretendo esclarecer aqui o quanto essa cisão ou abordagem bivetorial dá margem a armadilhas. Cindir a história e teoria do cinema entre os vetores formalista e realista implica soterrar as sutilezas de ambas as vertentes e considerar que um cineasta ou teórico formalista, a rigor, seria refratário ao realismo - e vice-versa. É necessário ressalvar aqui que essa abordagem bivetorial é, muitas vezes (e talvez sempre), o produto de releituras em retrospecto. Tentarei evitar as vicissitudes desse processo, porém, ao longo deste trabalho, determinados autores serão tratados a partir de uma divisão teórica 
apontada por outros autores - como no caso da revisão que Victor Perkins faz dos pensamentos de Rudolf Arnheim, Vsevolod Pudovkin, Sigfried Kracauer e André Bazin, entre outros, reforçando uma abordagem bivetorial. Mas antes de me aprofundar nessas questões, é útil retomar a teoria do cinema sob uma perspectiva histórica.

\section{PANORAMA HISTÓRICO DA TEORIA DO CINEMA}

Susan Hayward divide a história da teoria do cinema em três fases que se alternam entre o pluralismo e o monismo teóricos. Assim, entre os anos 1910 e 1930, período correspondente à emergência da teoria do cinema, teria prevalecido o pluralismo. Dos anos 1940 aos 1960, emerge o monismo de teorias totalizantes. E de 1970 até os anos 2000, observa-se um retorno ao pluralismo (Hayward, 2006: 410).

Entre os anos 1910 e 1930, destacam-se, no pensamento cinematográfico, os trabalhos de Louis Feuillade, com seu manifesto "Le film esthétique" (1910), Ricciotto Canudo, com seu ensaio "Naissance d'un sixième art" (1911), Vachel Lindsay, com seu livro The Art of the Moving Picture (primeiramente publicado em 1915, e revisado em 1922), e Hugo Münsterberg, com seu livro The Photoplay: A Psychlogical Study (originalmente publicado em 1916, e aqui investigado numa edição de 1970). Feuillade propunha que o cinema fosse uma arte a um só tempo popular e econômica, baseada numa sinergia entre tecnologia e estética e numa economia artística que envolvesse organicamente a arte e o capital. Em "O nascimento de uma Sexta Arte", Canudo anuncia a promessa de uma sexta arte emergente, o cinema, arte plástica em movimento, a partir de uma evolução do cinematógrafo, técnica por demais afeita a seu potencial de reprodução objetiva (assim como a fotografia) e, portanto, à qual ainda não seria possível conferir o estatuto de arte. Em The Art of the Moving Picture, Lindsay oferece, também em tom ensaístico, diversas impressões acerca da jovem arte cinematográfica (algumas de fato inspiradoras), sempre cotejando o cinema com as demais artes e à luz de modelos de crítica oriundos da literatura ou das artes plásticas.

Lindsay cita três "gêneros": ação, intimidade e esplendor. Para definir o cinema, recorre ao exemplo de outras artes, percebendo-o simultaneamente como "escultura em movimento", "pintura em movimento" e "arquitetura do movimento", com o movimento, portanto, constituindo o substrato comum da definição (a orientação visual de Lindsay não surpreende, haja vista a sua formação em pintura no Art Institute de Chicago). (Stam, 2003: 44) 
1. Todas as citações foram traduzidas por mim.
Num esforço pioneiro de teoria do cinema de maior fôlego, Hugo Münsterberg defende, em The Photoplay: A Psychlogical Study, que o cinema (ao qual dá o nome de photoplay) não é realidade filmada, mas um processo psicológico e estético que revela nossas experiências mentais:

A photoplay nos conta a estória humana por meio da manipulação de formas do mundo exterior, nomeadamente o espaço, o tempo e a causalidade, e por meio do ajuste de eventos às formas do mundo interior, ou seja, a atenção, a memória, a imaginação e a emoção. (Münsterberg, 1970: 74, grifos no original) ${ }^{1}$

As afirmações de Münsterberg não sonegam a associação do cinema a uma técnica de reprodução mecânica e objetiva da natureza (a começar pelo próprio termo photoplay), porém concentram-se sobre as relações. Esse espaço de interface, um espaço processual ou transicional ocupado pelo cinema e marcado por operações de subjetividade humana, é o campo de investigação preferencial de Münsterberg, conforme se depreende de passagens como a seguinte:

A photoplay nos mostra um conflito significante de ações humanas em filmes os quais, liberados das formas físicas de espaço, tempo, e causalidade, são ajustados ao jogo livre de nossas experiências mentais e atingem o isolamento completo do mundo prático por meio da perfeita unidade da trama e aparência pictórica. (Ibid.: 82 , grifos no original)

Münsterberg conclui sua obra com uma afirmação auspiciosa:

Pela primeira vez o psicólogo pode observar o começo de um desenvolvimento estético completamente novo, uma nova forma de verdadeira beleza no turbilhão de uma era técnica, criada pela própria técnica e ainda assim, mais do que qualquer outra arte, destinada a se apropriar da natureza exterior por meio da livre e gratificante ação da mente. (Ibid.: 100)

Vale a pena observar aqui a prevalência (ou, melhor dizendo, maior visibilidade) do pensamento cinematográfico gestado em meios francófonos e anglófonos. A perspectiva historiográfica da teoria do cinema permanece essencialmente eurocêntrica, e talvez seja pertinente, hoje, um esforço maior de pesquisas sobre a eclosão do pensamento cinematográfico mais sistemático (teórico) em outras partes do mundo. Não haverá espaço aqui para maiores incursões nesse debate acerca do imperialismo cultural, mas a prevalência da teoria do cinema anglófona e francófona é facilmente perceptível na própria 
bibliografia mobilizada neste estudo, representativa de um lugar de fala que responde também pela recorrência ao paragone e preferência pela abordagem dicotômica (formalismo vs. realismo).

Com o fim da Primeira Guerra Mundial, ampliam-se as discussões envolvendo tópicos como alta e baixa cultura, realismo vs. naturalismo, recepção, montagem, simultaneidade, subjetividade, psicanálise e inconsciente, autoria vs. script-led cinema, ritmo, signo e significação, entre outros aspectos. Com o advento do cinema sonoro, na virada da década de 1920 para 1930, emergem questões como a da morte do experimentalismo, do fim da arte cinematográfica e da busca por um cinema total.

Entre os anos 1940 e 1960, mas particularmente após 1946, os esforços convergem para a busca de uma teoria total do cinema. Destacam-se, no período, propostas como a de Alexandre Astruc e seu conceito de caméra-stylo (a câmera-caneta), e duas correntes teóricas principais ganham corpo: a teoria de autor (autorismo ou auteur theory, uma derivação da Política dos Autores), nos anos 1950, e a semiologia do cinema, nos anos 1960. O autorismo estruturalista (auteur-structuralism) substitui a teoria de autor nos anos 1960.

Entre os anos 1970 e 2000, com a crise das teorias totalizantes e o advento do pós-estruturalismo, entra em cena uma variedade de vetores de pensamento. Por exemplo, na esteira da teoria da Desconstrução, de Jacques Derrida, ganham vulto discussões envolvendo a importância da intertextualidade e dos efeitos ideológicos, do posicionamento ou papel do sujeito e dos efeitos da enunciação sobre o espectador (performance). No ambiente anglo-saxão emerge o Feminismo nos estudos de cinema, de maneira que o debate sobre subjetividade e agenciamento, esquecido desde os anos 1920, é reaberto (Hayward, 2006: 413). A reboque dessas transformações, emergem ainda o programa cognitivista, o semiopragmatismo e a semiótica cognitiva, entre outros vetores de pensamento.

A virada cognitivista nos anos 1980 beneficia-se do aporte das ciências cognitivas nos estudos de cinema, e emerge em certa medida como resposta às Grandes Teorias - como a psicanálise e a semiótica. O programa cognitivista propõe que a teoria não seja encaixada no filme, nem que o filme ilustre a teoria. Nesse sentido, a análise de problemas do filme suscitaria a formulação de uma constelação de microteorias (problem-driven theories).

Em The Cognitive Semiotics of Film, Warren Buckland (2000: 3) propõe um modelo de abordagem histórica da teoria do cinema no qual se observa, num primeiro momento, a emergência e consolidação da (1) teoria clássica do cinema, organizada em torno de dois eixos principais, o dos (a) montagistas (que agrupa autores como Rudolf Arnheim, Sergei Eisenstein etc.) e o dos (b) 
realistas (representado sobretudo por Sigfried Kracauer e André Bazin). Sobrevém à teoria clássica a (2) teoria moderna do cinema (também conhecida como teoria contemporânea do cinema), subdvidida em (a) semiótica do cinema (o Christian Metz de A Significação no Cinema e Cinema e Linguagem) e (b) teoria pós-estruturalista do cinema (Segunda Semiótica ou Psicossemiótica, abarcando teorias marxistas e psicanalíticas do cinema, como as de Stephen Heath, Colin MacCabe, o Christian Metz de O Significante Imaginário, Jean-Louis Comolli, Jean-Louis Baudry e Raymond Bellour, entre outros autores). Buckland observa que a transição de $2 \mathrm{a}$ para $2 \mathrm{~b}$ teria sido efetuada por teorias da enunciação baseadas na linguística de Benveniste. Num terceiro momento, emerge a (3) teoria cognitivista do cinema, expressa pelo trabalho de autores como David Bordwell, Noel Carroll, Edward Branigan, Joseph Anderson, Torben Grodal, Ed Tan, Murray Smith e outros. Finalmente, Buckland propõe um quarto estágio na história da teoria do cinema, no qual emerge a (4) semiótica cognitiva do cinema (desenvolvimento de 2a). Essa semiótica cognitiva do cinema estaria representada por (a) novas teorias da enunciação (Francesco Casetti, o Metz de A Enunciação Impersonal), (b) a semiopragmática do cinema (Roger Odin), e (c) a gramática generativa transformacional e semântica cognitiva do cinema (Michel Colin, Dominique Chateau).

Neste estudo, interessa-me circunscrever particularmente a teoria clássica do cinema e seus antecedentes. Pretendo investigar, aqui, problemas no modelo que organiza os primórdios da teoria do cinema e o classicismo teórico em torno de duas correntes supostamente antagônicas, o formalismo e o realismo. Esse modelo é recorrente numa variedade de abordagens históricas da teoria do cinema (Cf. Perkins, 1976; Buckland, 2000: 3).

Com relação específica à teoria clássica do cinema, com ênfase nos primórdios da teoria do cinema, vale a pena a remissão ao texto de V. F. Perkins, "A critical history of early film theory" (1976). Nesse ensaio, Perkins procede a uma atenta revisão dos principais vetores de pensamento numa fase em que o objetivo principal de críticos, teóricos e cineastas era legitimar o cinema enquanto forma de arte. Entre os autores citados por Perkins estão Vachel Lindsay, Rudolph Arnheim, Paul Rotha, Vsevolod Pudovkin e Béla Balász - curiosamente, Ricciotto Canudo não ganha a devida atenção de Perkins -, além de cineastas como Abel Gance, Walter Ruttman e Germaine Dulac. Perkins oferece uma visão negativa dessa primeira teoria do cinema, fase em que "a preocupação do teórico com o prestígio limitou severamente sua liberdade para investigar e especular acerca da natureza dos filmes" (1976: 403). Ele aponta exageros, devaneios e vicissitudes na argumentação dos primeiros teóricos, alguns persistentes no panorama da teoria do cinema subsequente. 
Por exemplo, segundo Perkins (1976: 403), o esforço de Arhneim por aplicar ao cinema os mesmos cânones e princípios de toda outra arte teria resultado muito mais em danos que benefícios.

De acordo com Perkins, a primeira teoria do cinema foi vítima de sua própria busca obsessiva pela consagração do cinema como forma de arte, sucumbindo ao radicalismo de determinadas proposições, e à cegueira em relação a outras propostas. Ainda segundo Perkins, o que teóricos pioneiros como Rotha e Arnheim propugnavam era por demais descolado do que os cineastas vinham experimentando à mesma época, de maneira que a primeira teoria do cinema incorreu em normativismo dogmático e ignorância acerca dos reais desenvolvimentos da sétima arte. O formalismo de Arnheim, Rotha, Balász e Pudovkin, cristalizado na noção de arte como "diferença-da-realidade" e na montagem como específico fílmico (o grande diferencial do cinema em relação a outras artes) é alvo preferencial de Perkins: "[v]isto assim como a essência criativa do cinema, a diferença-da-realidade é elevada ao status de critério. Porque 'a arte só começa onde a reprodução mecânica termina"' (Ibid.: 404). Perkins remete aqui a Pudovkin, para quem

o processo de filmagem não é a fixação pura e simples do que acontece na frente da câmera, mas sim uma forma peculiar de representação deste fato. Entre o evento natural e sua aparência na tela há uma diferença bem marcada. É exatamente essa diferença que faz do cinema uma arte. (1983: 68)

Tal concepção avessa à capacidade de reprodução objetiva da natureza teria sido desastrosa para a primeira teoria do cinema, segundo Perkins, o qual critica também o esforço dos teóricos em isolar o elemento específico do cinema, aquilo que supostamente o singulariza em relação a todas as demais artes: "o clamor aqui é o de que a essência de uma forma pode ser encontrada por meio do isolamento de um de seus componentes" (Perkins, 1976: 405). Esse componente, em muitas ocasiões, foi encontrado na montagem - como em Pudovkin, para quem a "montagem construtiva" seria "um método específica e particularmente cinematográfico" (1983: 65), sendo ainda que, "[i]gual à noção de tempo, a de espaço fílmico vincula-se também ao processo principal do cinema, à montagem" (Ibid.: 69, grifos meus). Porém, segundo Perkins, o "componente descrito como essência não pode ser, na prática, observado em seu estado puro" (Perkins, 1976: 405). Vale lembrar que André Bazin já havia comentado a respeito do problema da oscilação entre identificação e essencialismo, na verdade recorrendo a outros termos que, de certa maneira, significam noções equivalentes: impureza e autonomia. Defensor de um cinema 
impuro num dado momento, Bazin (2014) compreende a busca pela essência/ especificidade/autonomia do cinema numa perspectiva histórica:

é verdade que a história da arte evolui no sentido da autonomia e da especificidade. $\mathrm{O}$ conceito de arte pura (poesia pura, pintura pura etc.) não é desprovido de sentido; ele se refere a uma realidade estética tão difícil de definir quanto de contestar. Em todo caso, se certa mistura de artes ainda é possível, como a mistura de gêneros, não decorre daí que qualquer mescla seja bem-sucedida. (Bazin, 2014: 120)

Ao conjunto das primeiras teorias formalistas do cinema, as quais abriram espaço para a consagração do cinematógrafo enquanto arte, Perkins dá o nome de "teoria estabelecida" ou "teoria ortodoxa do cinema". A ortodoxia no pensamento cinematográfico teria privilegiado a forma em detrimento dos conteúdos, e dado corpo ao que o autor define como "dogma imagem". Perkins observa que a "ideia de que a montagem 'se assemelhava à criação' dominava o desenvolvimento da ortodoxia. A montagem tornou-se identificada com a linguagem criativa do cinema" (Perkins, 1976: 409, grifos no original). Ainda segundo Perkins, a "última e menos válida extensão da mística é a crença de que a montagem fornece não apenas a linguagem dos filmes, mas uma definição da natureza artística do cinema: nas palavras de Rotha 'a essência intrínseca da criação fílmica"' (Ibid.: 409). Perkins é absolutamente crítico dessa posição formalista e da consagração da montagem como específico fílmico. Segundo ele,

Se isolamos a montagem do complexo que inclui os movimentos de atores, a forma do cenário, o movimento e câmera, e variações de luz e sombra - os quais mudam dentro dos planos em separado tanto quanto entre eles - não deveremos entender nenhum desses elementos (e certamente não a montagem também), pois cada um deles deriva seu valor da relação que mantém com os demais. (Ibid.: 410)

Em linhas gerais, Perkins é excessivamente severo com os cineastas/teóricos associados ao formalismo cinematográfico, como quando afirma que os "campeões da montagem e da imagem nunca souberam o que fazer com o som" (Ibid.: 420). Observação exagerada, senão completamente equivocada, uma vez que Eisenstein, por exemplo, dedicou número razoável de linhas e experimentos cinematográficos acerca do som no cinema, conforme podemos verificar em sua proposta de "montagem vertical" (na qual a ideia de conflito é transportada do choque entre dois planos para o choque entre as bandas so- 
nora e imagética) e em uma variedade de seus escritos nos volumes A Forma do Filme (2002a) e O Sentido do Filme (2002b). ${ }^{2}$ Até sobre o cinema 3D estereoscópico (S3D) Eisenstein especulou teoricamente, em ensaio originalmente publicado em 1947 (Cf. 2013: 20-59).

Para Perkins, só a emergência do pensamento cinematográfico realista (a partir da obra de autores como Bazin e Kracauer) consegue redimir excessos e vicissitudes da ortodoxia, trazendo um pouco de justiça às conquistas estéticas de cineastas como Erich Von Stroheim, Max Ophüls ou Jean Renoir, entre outros. Perkins relembra que Bazin acusou os teóricos ortodoxos de terem trocado a verdadeira vocação do cinema, que é a primazia do objeto, pela suposta primazia da imagem (1976: 419). No entanto, embora penda sua balança a maior parte do tempo em favor do realismo, finalmente Perkins não isenta Bazin e Kracauer de exageros e distorções. Sobre Bazin, Perkins admite que "[s]ua visão tende à criação de um dogma tão limitador quanto o criado pela ortodoxia" (Ibid.: 420). A reação à ortodoxia teórica do cinema e ao seu "dogma imagem", manifesta no pensamento realista, teria exagerado em diversos momentos, originando seu próprio "dogma objeto". O autor conclui observando que:

Bazin confundiu sua própria vocação crítica em defesa do realismo com a "verdadeira vocação do cinema". Suas asserções teóricas ameaçam com um purismo do objeto tão estreito quanto aquele da imagem. Malgrado as qualificações e anúncios cuidadosos de Bazin, a teoria realista se torna coerente apenas se identificamos a "essência" do cinema com um único aspecto do filme - a reprodução fotográfica. Ao definir o filme por meio da referência a uma de suas características, a teoria realista se assemelha à ortodoxia, na medida em que ela constrói um critério a partir de uma preferência por aspectos particulares da técnica cinematográfica. Ambas as teorias discriminam em favor de certos tipos de efeito cinemático, em outras palavras, certos tipos de atitude em relação a uma dada forma cinemática. O dogma imagem julga a qualidade em termos da imposição de ordem, pelo artista, à superfície caótica e sem sentido da realidade. $\mathrm{O}$ dogma objeto derivaria seu veredito de sua descoberta de ordem e significância na realidade. Cada uma dessas posições pressupõe uma filosofia, um temperamento, uma visão - terreno que os teóricos deveriam deixar aberto para que o cineasta o explore e apresente. (Ibid.: 421, grifos no original)

Pretendo demonstrar aqui que, para além de um balanço crítico das posições formalistas e realistas no panorama da teoria clássica do cinema e seus antecedentes, talvez seja útil questionar essa divisão em trincheiras ideológicas, 
a qual pode ser uma perspectiva operacional essencialmente retrospectivista e simplificadora das reais complexidades que marcavam o pensamento cinematográfico na primeira metade do século XX.

Nesse sentido, proponho que avancemos da usual releitura de autores por outros autores para o exame de dois textos básicos de Ricciotto Canudo, autor ao qual se atribui noções-chave para o desenvolvimento da primeira teoria do cinema, como a ideia de sétima arte e a própria controvérsia entre formalismo e realismo. Até esse momento, boa parte dos argumentos desenvolvidos e das divisões dos campos teóricos foi feita a partir de autores se pronunciando acerca de outros autores (como no caso de Victor Perkins). Passemos agora a uma fonte importante, porém por vezes esquecida.

\section{RICCIOTTO CANUDO}

Ricciotto Canudo, crítico italiano radicado na França, é autor de dois ensaios especialmente úteis a esta investigação: "Naissance d'un sixième art" (originalmente publicado em Les Entretiens Idéalistes de 25 de outubro de 1911) e "Réflexions sur le septième art" (texto originalmente publicado em 1923 e reproduzido em L'Usine aux Images, 1926).

Em "Naissance..., Canudo refere-se ao cinema não ainda como arte estabelecida, mas como arte nascente, em potencial. O cinema seria, assim, a síntese de cinco artes ancestrais: arquitetura, escultura, pintura, música e poesia (literatura), "reconciliação soberba dos Ritmos do Espaço (Artes Plásticas) e dos Ritmos do Tempo (Música e Poesia)" (Canudo, 1988: 59). O autor soma, mais tarde, a dança, uma terceira arte rítmica, à música e à poesia, alçando o cinema ao status de Sétima Arte. Em seu entusiasmo por saudar as potencialidades artísticas do cinema, Canudo recorre a paralelos com artes consagradas (paragone), como na passagem a seguir:

A nova manifestação da Arte [o cinema] deveria ser realmente mais precisamente uma Pintura e uma Escultura desenvolvidas no Tempo, como na música e na poesia, as quais se realizam transformando ar em ritmo pela duração de sua execução. (Ibid.: 59)

O cinematógrafo promove, nos termos de Canudo, o advento de uma "Arte Plástica em Movimento" (Plastic Art in Motion) (Ibid.: 59). O autor destaca ainda dois aspectos fundamentais ao cinematógrafo: o simbólico e o real (Ibid.: 59-60). O aspecto simbólico é a velocidade: velocidade do rolo de filme girando no projetor, velocidade dos objetos em movimento representados na 
tela luminosa. $\mathrm{O}$ aspecto real diz respeito aos elementos que despertam o interesse e maravilhamento do público moderno: o registro fotográfico (acrescido do valor do movimento) da realidade, das atualidades. Ainda segundo Canudo, o cinematógrafo "representa o todo da vida em ação" (Canudo, 1988: 61), sendo produto da cultura ocidental, uma "cultura da ação" em oposição à cultura oriental da contemplação - europeu, Canudo incorre num eurocentrismo típico de seu tempo e numa concepção do "Outro" que só seria desmistificada muitos anos depois, com a publicação de obras como Orientalismo (originalmente publicada em 1978), de Edward Said. A influência do Futurismo italiano nesse ensaio de Canudo pode ser apreendida na exaltação que o autor faz da velocidade, como na passagem em que indaga:

Quem ainda é capaz de desfrutar de um cachimbo em paz perto da lareira por estes dias, sem ouvir o ruído tonitruante dos carros em movimento lá fora, noite e dia, em todas as direções, um desejo irresistível por espaços a se conquistar? (Ibid.: 60).

Mas o fato é que, muito embora guarde em potência e prometa todas as graças de uma nova forma de arte, atualíssima e magnânima, o cinema de seu tempo, segundo Canudo,

[a]inda não é uma arte porque carece da liberdade de escolha peculiar à interpretação plástica, está condicionada a ser a cópia de um assunto ou objeto, a mesma condição que impede a fotografia de se tornar uma arte (Ibid.: 61, grifos no original).

Convém notar que Canudo dosa muito bem o uso dos termos cinematógrafo e cinema, associando o primeiro a uma técnica popular, produto da indústria e da ciência, e o segundo a uma arte nascente. Ainda segundo o autor,

As Artes são tanto maiores quanto menos imitam e mais evocam por meio de uma síntese. Um fotógrafo, por um lado, não tem a faculdade da escolha e elaboração fundamentais à Estética; ele pode apenas juntar as formas que deseja reproduzir, as quais ele realmente não está reproduzindo, limitando-se a enquadrar imagens com a ajuda do mecanismo luminoso das lentes e de um composto químico. $\mathrm{O}$ cinematógrafo, portanto, não pode ser uma arte hoje. Mas por diversas razões, o teatro cinematográfico [a sala de cinema] é a primeira residência da nova arte - uma arte que agora mal podemos conceber. Pode essa residência se tornar o "templo" para a estética? (Ibid.: 62, grifos no original) 
Emerge aqui, de forma clara, a tese formalista fundamental, a de que uma arte não se baseia na reprodução mecânica e objetiva do mundo, mas, sim, em sua capacidade expressiva de criação de um novo mundo, à imagem da vontade e dos sentimentos do artista. Essa noção, muito em voga na esteira do Pós-Impressionismo, relegava o grosso das atualidades e travelogues ao status de mera curiosidade ou divertimento inculto. Os argumentos de Canudo citados, portanto, estão na origem das teses de Rudolph Arnheim e Paul Rotha, e serão revisitados pelos assim chamados teóricos da montagem soviéticos (Pudovkin, Vertov, Eisenstein), invariavelmente.

Embora Canudo interdite o status de arte ao cinema de sua época, baseado na carência de expressividade artística do cinematógrafo, o crítico não poupa elogios à capacidade representacional dessa arte-em-potência, "esta nova representação mimética de uma 'vida total'” (Canudo, 1988: 62), exaltando também seu potencial educativo - é tentador, aqui, identificar um gérmen do mito de um cinema total.

O cinematógrafo traz, em meio à menor das comunidades humanas, o espetáculo de coisas distantes, agradáveis, emocionantes ou instrutivas: ele espalha cultura e estimula em toda parte o desejo eterno pela representação da vida em sua totalidade. (Ibid.: 65)

O trecho citado acena com argumentos que serão substancialmente desenvolvidos por dois autores posteriores a Canudo, Sigfried Kracauer e André Bazin, defensores ardorosos do realismo cinematográfico. O ponto aqui é que a tese da objetividade fotográfica inerente ao cinema, da arte que se beneficia de uma escrita automática do mundo, já pode ser claramente entrevista no seguinte trecho de Canudo:

Repentinamente, o cinematógrafo se tornou popular, somando a um só tempo todos os valores de uma ainda eminente era científica, confiada ao Calculus e não às operações da Fantasia, e impôs-se de maneira peculiar como um novo tipo de teatro, um teatro científico construído sobre cálculos precisos, um modo mecânico de expressão. (Ibid.: 60)

Ainda que não encontre exatamente nesses argumentos a legitimação do cinema como forma de arte, Canudo não os exclui do debate - aceita-os como características intercorrentes no fenômeno cinematográfico, e os sublinha de maneira nada distante do que apologistas do realismo cinematográfico farão tempos depois. 
Também em "Naissance..." pode ser encontrada uma possível origem da ideia de que o cinema seria, na verdade, um impulso criativo ancestral que remete a tempos pré-históricos, e cuja prova reside no achado das pinturas rupestres. Essa analogia é útil a Canudo em sua busca (paragone) pela distinção do cinema (aqui entendido como essencialismo) em relação às artes plásticas, consagradas pela virtude da captura de elementos do mundo objetivo sob o tratamento criativo (e subjetivo) do artista. Um primeiro e mais evidente traço dessa distinção seria o movimento. Segundo Canudo,

Os pintores e gravadores ancestrais das cavernas pré-históricas, que reproduziam com ossos de alces os movimentos contraídos de um cavalo galopante, e os artistas que esculpiam procissões nos frisos do Parthenon, também desenvolveram o dispositivo de estilização de certos aspectos da vida em momentos claros e incisivos. Mas o cinematógrafo não apenas reproduz um aspecto; ele representa a vida como um todo em ação. (Canudo, 1988: 61)

Doze anos depois, em "Réflexions sur le septième art", Canudo continua sua defesa do cinema como forma de arte. Novamente é possível observar a oscilação entre a identificação e o essencialismo - com ênfase no segundo. Canudo já inicia seu ensaio argumentando que o cinema (e aqui o autor usa mais livremente o substantivo cinema) eclode de pesquisas industriais e científicas, e que na França, mais do que em qualquer outro lugar, predomina a ignorância do fato de que o cinema é uma arte que "não deve se parecer com nenhuma outra" (Ibid.: 291).

Uma pequena semente do realismo baziniano pode ser entrevista quando Canudo afirma que, "[e]ntretanto, a natureza como personagem é outro domínio absoluto do cinema” (Ibid.: 292, grifos no original). Não obstante, tendo em vista a aderência de Canudo às teses formalistas da arte, não surpreende que logo em seguida o autor saúde com entusiasmo o cinema expressionista alemão, notadamente o poder expressivo do décor em filmes como O Gabinete do Dr. Caligari (Das Cabinet des Dr. Caligari, 1919), de Robert Wiene, e Da Aurora à Meia-Noite (Von Morgens bis Mitternacht, 1922), de Karl Heinz Martin, além do impressionismo francês ocasional do Abel Gance de A Roda ( $L a$ Roue, 1923) (Ibid.: 292; 294). Radicalizando o formalismo, e em concordância com seu elogio aos expressionistas, Canudo sentencia que o real só pode ser encontrado de fato na poesia:

Entre a atmosfera de irrealidade sintetizada pelos designers do filme alemão, e a atmosfera de igual irrealidade sintética "engendrada" no filme francês de Gance, 
há a realidade absoluta: o sonho do artista, Poesia. Como Novalis diz, Poesia é o Real absoluto. (Canudo, 1988: 294).

Por conseguinte, a ideia de uma "linguagem cinematográfica" não tarda a aparecer em "Réflexions..., a noção do cinema enquanto uma linguagem universal, cujo domínio garantiria o estatuto de arte à, outrora, mera reprodução mecânica da realidade.

Assim, a linguagem cinematográfica, mesmo exterior à história que anima, procura febrilmente seu discurso, articulando suas sílabas, lutando por uma pronunciação óptica. Até agora ela tem carecido de elegância, ou agradável espontaneidade. (Ibid.: 295)

3. Lembremos que o ensaio "Uma inesperada junção" (Nezhdannii styk), de S. M. Eisenstein, foi escrito em 1928 e publicado na revista Vida das Artes (Zhinz Iskusstva) n. 34, e "Fora de Quadro" (Za Kadrom), escrito em fevereiro de 1929, foi publicado em 1930 na revista francesa Transitions com o titulo "O princípio cinematográfico e a cultura japonesa". Em 1949, esse mesmo ensaio saiu publicado em Film Form com o título "O princípio cinematográfico e o ideograma". Analogias entre a linguagem cinematográfica e a escrita ideográfica, assim como aspectos da controvérsia entre identificação e essencialismo, reaparecem numa variedade de textos de Eisenstein, como em "Do Teatro ao Cinema" (título original Srednaia iz trekh, 1924/29), escrito em 1934 e publicado na revista Sovietskoie Kino

n. $11 / 12$ de dezembro do mesmo ano (Cf. Eisenstein, 2002a).
O paradigma linguístico que se apresenta em Pudovkin e sobretudo Eisenstein, depois revisitado e revisto pelo cine-estruturalismo, já se pronuncia aqui. Nas linhas subsequentes, Canudo fornece ainda mais munição para o dogma imagem, e logo se refere aos alfabetos e ideogramas, analogia cara a Eisenstein ${ }^{3}$.

Línguas ideográficas como o chinês, ou sistemas hieroglíficos como o egípcio, manifestam ainda visivelmente sua origem em imagens.

O cinema, por seu turno, se beneficia e multiplica as possibilidades da expressão em imagens que até então eram a província da pintura e da escultura. Ele deve construir uma verdadeira língua universal com características até então jamais sonhadas. (Ibid.: 296)

Não obstante, no mesmo parágrafo Canudo exalta aspectos do cinema que estão no cerne do pensamento realista que se constituiu em suposta oposição ao formalismo e ao paradigma linguístico.

A chegada do cinema herda uma renovação de todos os modos de criação artística, de todos os meios de "captura do fluxo", de conquista do efêmero. O que ele já pode nos mostrar - por exemplo, no estudo em câmera lenta do crescimento das plantas - é uma afirmação de sua estupenda capacidade de renovar a representação da própria vida, fixando instante-a-instante o movimento de seres e coisas. $\mathrm{O}$ cinema nos dá uma análise visual de tamanha evidência precisa que ele não pode senão enriquecer vastamente a imaginação poética e pictórica. Além disso, por meio de sua dimensão "horizontal" - sua capacidade de mostrar eventos ocorrendo em simultaneidade - ele irá incrementar a soma total de nossas sensações. (Canudo, 1988: 296, grifos no original) 
O mesmo parágrafo termina com uma imagem que poderia remeter às ideias de decalque do real e paralelepípedo do real tão caras a Bazin (2014): a "tela, este livro de uma só página tão único e infinito quanto a própria vida, permite que o mundo - tanto interna como externamente - seja impresso em sua superfície (Canudo, 1988: 296).

Canudo vai consagrar suas linhas seguintes a uma crítica do cinema francês e dos interesses comerciais envolvidos - diatribe que soa familiar mesmo que transposta aos anos 1950, no contexto da emergente "Política dos Autores" (1988: 297) -, para em seguida retomar sua crítica ao "teatro filmado" (1988: 297). A oscilação entre identificação e essencialismo reaparece nesse contexto:

Se o cinema é mais que apenas teatro fotografado, ou um romance realista ilustrado, todos os atores devem ser articulados em função da luz, tal como pintores expressaram os fantasmas de seus sonhos por meio do jogo de cores. O filme, a obra, então aparecerá em seu próprio direito, independente das outras artes, não necessitando de intertítulos exageradamente explícitos ou falas mimetizadas, livre dos grilhões convencionais do teatro. (Canudo, 1988: 298)

A seguir, Canudo reforça seu apreço pelo poder de sugestão do cinema, sua aposta na representação cinemática de emoções e no potencial cinematográfico de provocar emoções no público - noção próxima do cinema preconizado por D. W. Griffith, revisado e desenvolvido por Eisenstein (2002a). Usando o termo "écraniste" para se referir ao cineasta, Canudo debate aqui seu conceito de "verdade cinemática" (parte IV de "Réflexions..."), e retoma o fogo contra a mera reprodução objetiva da realidade.

Mas se o écraniste foi bem-sucedido em situar a ação no contexto psicológico maior, se foi bem-sucedida em minha preparação acerca das emoções que ele sente, então eu responderei da maneira que ele deseja. (...)

No cinema, assim como nas buscas da mente, a arte consiste em sugerir emoções, e não em recontar fatos. (...)

Apenas alguns écranistes têm entendido que a verdade cinematográfica deve corresponder à verdade literária, à verdade pictural, mesmo à verdade do amor. Nenhuma dessas é a "realidade” objetiva. (Canudo, 1988: 299)

Nos textos de Canudo estão sementes de argumentos tanto favoráveis ao dogma da imagem (formalismo) quanto ao dogma do objeto (realismo). Tanto o essencialismo quanto a identificação, tanto a condenação do naturalismo 
representacional quanto o elogio medido do realismo. Nesse sentido, a prosa de Canudo pode ajudar involuntariamente a esclarecer um problema fundamental. O problema consiste nas seguintes paridades teóricas: identificação vs. essencialismo; formalismo vs. realismo. Se essencialismo e identificação podem ser consideradas categorias paritárias, comensuráveis ou correlacionáveis (o movimento para longe ou para próximo das demais artes), formalismo e realismo não podem. Em outras palavras, posso argumentar que o cinema engloba ou se assemelha a outras artes, ou que o cinema na verdade se distingue de outras artes por tais e tais motivos. Posso ainda esclarecer que o cinema se assemelha às demais artes em tais e tais aspectos, e se distancia, ou se singulariza (em relação às demais artes), por outros tais e tais aspectos. Mas não há como afirmar, definitivamente, que o interesse (ou fé, em termos bazinianos) na forma (imagem) invalida o interesse (ou fé) no real ou na realidade - enfim, no mundo empírico, os objetos do mundo como apreendidos por nossos sentidos.

\section{EMBATES EM REVISÃO}

Tal polêmica é extensa e mobiliza uma variedade de autores, inclusive aspectos da filosofia e da filosofia do cinema aos quais não pretendo me endereçar agora. No entanto, por ora, gostaria de salientar que a cisão do pensamento cinematográfico entre duas trincheiras ideológicas, a formalista e a realista, reduz a complexidade das agendas teóricas do cinema em diferentes momentos da história. Vale lembrar que essa mesma cisão espelha, em certa medida, outra divisão, a qual também já foi apontada como excessivamente redutora. Trata-se daquela que elegeu, como em Georges Sadoul (1983), os irmãos Lumière e Georges Méliès como respectivos pais ou fundadores de duas vertentes cinematográficas: o documentário e/ou o cinema de orientação naturalista, e o filme de fantasia e/ou o cinema de tendência formalista. Desnecessário aqui esmiuçar as fraquezas dessa falsa genealogia cinematográfica.

Não é denominador comum às vanguardas (dentro ou fora do cinema) - salvo os momentos mais extremados do Expressionismo e do Surrealismo, por exemplo, e movimentos como o do cinema puro ou do cinema abstrato - o desapreço ao mundo empírico ou a questões de objetividade da representação. Pode parecer óbvio, mas não custa lembrar que a Escola da Montagem Soviética, considerada um movimento de vanguarda no contexto da história do cinema, nunca se definiu em oposição à realidade, ao mundo empírico e histórico, e quiçá em contrapartida ao realismo. Seria, no mínimo, despropositado associar o rótulo de irrealista a cineastas como Dziga Vertov ou Serguei Eisenstein - ainda que ambos tivessem concepções muito particulares de tra- 
tamento da realidade. O fato é que o cine-olho (kino-glaz) de Vertov (1983) ou o cine-punho de Eisenstein - e sua "montagem de atrações" (1983) - nunca se constituíram em oposição à realidade do mundo empírico, talvez, muito pelo contrário. Não é nada absurdo, a partir de uma leitura cuidadosa dos manifestos e ensaios assinados por Vertov e parceiros (os kinoks), mas sobretudo por Eisenstein, localizar uma orientação realista muito precisa por trás de especulações sobre a forma artística. Um determinado tipo de realismo modernista ou de vanguarda, no espírito de Brecht, segundo o qual

Uma fotografia da fábrica Krupp ou da A.E.G. quase nada prova dessas instituições. A realidade autêntica resvala e cai no funcional. A concretização das relações humanas, a fábrica, digamos, não reproduz já essas últimas. É, pois, em realidade, "algo a construir", algo "artificial", algo "posto". (1984: 113)

Em Brecht, realismo e forma tornam-se a tal ponto amalgamados que já não se pode mais classificar esse artista em termos de velhas oposições binárias. Vejamos, por exemplo, em "O nascimento do cine-olho", texto de Vertov publicado originalmente em 1924, o apelo relativo à "verdade", a "tudo o que podia servir para descobrir e mostrar a verdade" (1983: 262, grifos no original). Por mais controverso e difuso que esse termo possa ser, especialmente nesse contexto, não parece razoável divorciá-lo de uma intenção realista:

Não o "Cine-Olho" pelo "Cine-Olho", mas a verdade, graças aos meios e possibilidades do "Cine-Olho", isto é, o Cine-Verdade.

Não a tomada de improviso "pela tomada de improviso", mas para mostrar as pessoas sem máscara, sem maquilagem, fixá-las no momento em que não estão representando, ler seus pensamentos desnudados pela câmera. (Vertov, 1983: 262)

É possível objetar que a busca por tal verdade e a intenção realista apreensível no cinema e nas teses dos montagistas soviéticos estivessem equivocadas, ou fossem equivocadamente formuladas. Mas essa ponderação não é suficiente para divorciá-los de um programa estético realista lato sensu - divórcio que aparece com frequência em muitas abordagens retrospectivas e mesmo no ensino da história da teoria do cinema.

Em última análise, podemos supor que uma intenção, e até mesmo uma orientação realista, atravessa a maioria dos programas estéticos, escolas e movimentos que compõem a história do cinema.

A rigor, o pensamento cinematográfico formalista não exclui (salvo em alguns momentos de maior radicalismo) a dimensão objetiva das técnicas de 
reprodução aproximada da realidade, nem aspectos relativos ao conteúdo da imagem em movimento (seu referente externo), nem o suporte fotográfico da arte cinematográfica. Talvez essa submissão do conteúdo em favor da forma, conforme observado por Perkins (1976), seja menos prevalecente do que esse autor supõe acerca da teoria e prática de cineastas/teóricos comumente associados ao formalismo. Por exemplo, em seu ensaio "Eh! Sobre a pureza da linguagem cinematográfica", originalmente publicado em maio de 1934 na revista Sovietskoie Kino n. 5, Eisenstein observa que, “[p]ara muitos diretores, montagem e excessos esquerdistas de formalismo - são sinônimos. Porém, a montagem não é isso de modo algum" (2002a: 110). O cineasta complementa:

Não sou a favor, de modo algum, da "hegemonia" da montagem. Passou a época em que, com objetivos pedagógicos e de treinamento, era necessário realizar movimentos táticos e polêmicos para libertar amplamente a montagem como um meio expressivo do cinema. (Ibid.: 111)

Por outro lado, o pensamento realista não exclui a preocupação com a forma, muito menos a condena. Muito pelo contrário, o pensamento realista mais sofisticado (como em Bazin) sustenta um fino rigor formal, e padece de um normativismo estético tão limitador quanto aquele verificado no seio do pensamento formalista mais radical. Se o pensamento realista na teoria do cinema se constitui e se define em oposição ao pensamento formalista, o fato é que ambos enfatizam praticamente a mesma agenda de problemas, e uma questão em particular: o que é o cinema. Nesse sentido, fica difícil a análise de um em detrimento do outro, o descarte ou a desconsideração de aspectos de uma agenda em favor dos axiomas de outra. Em outras palavras, ser realista não implica subjugar a forma, assim como ser formalista não se caracteriza pelo desprezo ao conteúdo da imagem em movimento. Senão vejamos o seguinte trecho:

No momento, o cinema está prestes a abrir um novo caminho para a nossa cultura. Milhões de pessoas frequentam os cinemas todas as noites e unicamente através da visão vivenciam acontecimentos, personagens, emoções, estados de espírito e até pensamentos, sem a necessidade de muitas palavras. Pois as palavras não atingem o conteúdo espiritual das imagens e são meros instrumentos passageiros de formas de arte ainda não desenvolvidas. A humanidade ainda está aprendendo a linguagem rica e colorida do gesto, do movimento e da expressão facial. Esta não é uma linguagem de signos substituindo as palavras, como seria a linguagem-signo do surdo-mudo - é um meio de comunicação visual sem a mediação de almas envoltas em carne. O homem tornou-se novamente visível. 
Quem é o autor da passagem? Um simpatizante do realismo cinematográfico ou algum crítico do cine-língua? Não, é Béla Balász (1983: 79), no ensaio "O Homem Visível" (Der Sichtbare Mensch), de 1923 - texto contemporâneo do "Réflexions sur la Septième Art", de Canudo. Ainda segundo Balász, a "câmera descobriu a célula-mãe das matérias vitais nas quais todos os grandes eventos são, em última instância, concebidos: pois o maior pedaço de terra não passa de um agregado de partículas em movimento" (Ibid.: 90) - a quem serve essa observação, formalistas ou realistas?

Oportunamente, Christine Etherington-Wright e Ruth Doughty observam que o corte em continuidade, a montagem e o plano-sequência apresentam três formas distintas de se contar uma estória (2011: 48). No entanto, “[e] mbora a montagem soviética seja mais reconhecidamente associada com o Formalismo, todas essas três formas de se compor uma narrativa envolvem a seleção de uma forma e sua aplicação a um texto" (Etherington-Wright e Doughty, 2011: 48). Sobre Bazin, cuja defesa do realismo cinematográfico seria virtualmente oposta ao formalismo, Robert Stam explica:

$\mathrm{Na}$ verdade, Bazin é, em certos aspectos, um formalista, no sentido de se revelar menos interessado por qualquer "conteúdo" específico do que por um estilo de mise-en-scène. E tampouco pode ser reduzido a um teórico exclusivamente do realismo; suas ideias sobre gênero, autoria e "cinema clássico" também tiveram um enorme impacto. (2003: 96)

Vale lembrar ainda que, assim como Eisenstein (2002a: 110-111) depois reconheceu a ênfase na forma e montagem como uma necessidade política circunscrita a um determinado momento, Bazin também relativizou a função indexical do cinema, paradigma ao qual seu nome sempre foi tão associado:

O que se entende, com efeito, por "cinema" no problema crítico que nos interessa? Se é um modo de expressão por representação realista, por mero registro de imagens, uma pura visão exterior que se opõe aos recursos da introspecção ou da análise romanesca clássica, então é preciso observar que os romancistas anglo-saxões já haviam encontrado no behaviorismo as justificativas psicológicas de tal técnica. Mas, além disso, o crítico literário tem ideias imprudentemente preconcebidas do que é o cinema a partir de uma definição bem superficial de sua realidade. Não é porque a fotografia é sua matéria-prima que a sétima arte está fadada à dialética das aparências e à psicologia do comportamento. Se é verdade que ela só pode apreender seu objeto do exterior, há mil maneiras de agir sobre sua 
aparência para eliminar qualquer equívoco e fazer dela o signo de uma, e apenas uma, realidade interior. (Bazin, 2014: 121-122, grifos meus)

Convém não esquecer também que, mesmo à última linha de "Ontologia da imagem fotográfica” (texto tomado por muitos como espécie de manifesto do paradigma indexical), Bazin já relativizava a função da base fotográfica do cinema, abrindo-se à complexidade: "Por outro lado, o cinema é uma linguagem" (Ibid.: 34).

\section{CONSIDERAÇÕES FINAIS}

Assim, no caso específico de Ricciotto Canudo, cujos textos alimentaram em grande medida essa abordagem bipartidária (formalismo vs. realismo), é possível verificar a organicidade da relação entre os pensamentos acerca da forma e do conteúdo ou natureza da imagem cinematográfica. Embora Canudo não disfarce seu entusiasmo em relação ao paradigma formalista, seus dois ensaios aqui diretamente investigados oferecem argumentos úteis aos dois programas estéticos, desenvolvidos a posteriori tanto por teóricos formalistas quanto por pensadores do realismo. Tendo a crer que a abordagem bipartidária da teoria do cinema pode mais ofuscar do que esclarecer aspectos da evolução do pensamento cinematográfico como um todo, com implicações no entendimento contemporâneo do fenômeno cinematográfico e audiovisual. No lugar de dois eixos paralelos ou divergentes no contexto da história e teoria do cinema, uma forma mais produtiva de abordagem do formalismo e do realismo cinematográficos talvez seja tratá-los em termos de gradação, num mesmo continuum ou vetor - uma mesma linha cujas extremidades mais distantes de fato não respondem pela maior parte do pensamento produzido.

Finalmente, no contexto do cinema digital e das imagens pós-fotoquímicas, a precariedade da oposição formalismo $v$ s. realismo parece ainda mais evidente. Conforme apontado por Stephen Prince, a "imagem digital expõe a persistente dicotomia [formalismo $v s$. realismo] na teoria do cinema como uma falsa fronteira. Não se trata de o cinema registrar indexicalmente o mundo ou transformá-lo estilisticamente. O cinema faz ambos" (Prince, 1996: 35). O autor observa que

Enquanto a teoria clássica do cinema estava organizada em torno da dicotomia entre realismo e formalismo, a teoria contemporânea tem preservado essa dicotomia mesmo quando reconfigura algum desses termos. Hoje, noções de realismo cinematográfico baseadas na indexicalidade existem em tensão com uma visão semiótica do cinema como discurso e do realismo como um discurso entre outros. (Ibid.: 31) 
Prince se pergunta: face ao cinema digital, devemos descartar inteiramente noções do realismo no cinema? Sua resposta aponta para um modelo baseado em correspondência, num esforço de reconciliação do formalismo com o realismo no contexto dos estudos contemporâneos de cinema (pós-fotográficos) (Ibid.: 31). Ainda segundo Prince,

As tensões dentro da teoria do cinema podem ser superadas evitando-se uma concepção essencialista do cinema que enfatize propriedades únicas ou fundamentais e aplicando-se, no lugar de noções de realismo cinematográfico baseadas na indexicalidade, um modelo de representação cinemática baseado em correspondência. Tal modelo nos permitirá discutir e pensar tanto sobre imagens fotográficas quanto sobre imagens geradas em computador, e sobre as maneiras pelas quais o cinema pode criar imagens que parecem alternadamente reais e irreais. (Ibid.: 31 )

Nesse panorama, a atual reconfiguração do paradigma indexical, conduzida por transformações profundas na práxis do cinema (digital/pós-fotoquímico), sugere novos modelos de análise e novas abordagens de uma virtual história das teorias do cinema. Entre esses modelos estão os conceitos de realismo perceptual (perceptual realism), proposto por Gregorie Currie (1995) e desenvolvido por Stephen Prince (1996), e o modelo baseado em correspondência (correspondence-based model) (Ibid.: 31), substituindo o modelo indexical (indexically based). Independentemente da validade do modelo baseado em correspondência proposto por Prince (1996), o fato é que, no contexto das imagens digitais ou pós-fotoquímicas, modelos mais flexíveis e abrangentes parecem efetivamente necessários - bem como novas perspectivas de abordagem retrospectiva da teoria do cinema. $\mathbf{M}$

\section{REFERÊNCIAS}

BALÁSZ, B. O homem visível. In: XAVIER, Ismail (org.). A Experiência do Cinema. Rio de Janeiro: Graal, 1983. p. 77-83.

. A face das coisas. In: XAVIER, Ismail (org.). A Experiência do Cinema. Rio de Janeiro: Graal, 1983. p. 87-91.

BAUDRY, J. L. Ideological effects of the basic cinematographic apparatus. In: ROSEN, P. (ed.). Narrative, apparatus, ideology. Nova York: Columbia University Press, 1986. p. 286-298.

BAZIN, A. O Que é o Cinema?. São Paulo: Cosac Naify, 2014.

BRECHT, B. El processo de los tres centavos (1931). In: El compromisso en literatura y arte. 2. ed. Barcelona: Península, 1984, 2a ed. p. 95-152. 
BUCKLAND, W. The Cognitive Semiotics of Film. Cambridge/Nova York: Cambridge University Press, 2000.

CANUDO, R. Birth of a Sixth Art. In: ABEL, R. (ed.). French Film Theory and Criticism. Princeton: Princeton UP, 1988. p. 58-65. Réflexions sur le septième art. In: L'Usine aux Images. Paris: Etienne Chiron, 1926. p. 29-47. . Reflections on the Seventh Art. In: ABEL, R. (ed.). French Film Theory and Criticism. Princeton: Princeton UP, 1988. p. 291-302.

CURRIE, G. Image and Mind: Film, Philosophy, and Cognitive Science. Cambridge/Nova York: Cambridge University Press, 1995.

EISENSTEIN, S. M. A forma do filme. Rio de Janeiro: Jorge Zahar, 2002a. . O sentido do filme. Rio de Janeiro: Jorge Zahar, 2002b.

. On Stereocinema (1947). In: ADLER, D.; MARCHESSAULT, J.; OBRADOVIC, S. (eds.). 3D Cinema and Beyond. Toronto/Chicago: Public, 2013. p. 20-59.

ETHERINGTON-WRIGHT, C.; DOUGHTY, R. Understanding Film Theory. Londres: Palgrave-Macmillan, 2011.

FEUILLADE, Louis. "Le Film esthétique". Ciné-journal n 92, 28 mai 1910, p. 19.

HAYWARD, S. Cinema Studies: the Key Concepts. 3. ed. Londres/Nova York: Routledge, 2006.

LESSING, G. E. Laocoonte ou sobre as fronteiras da pintura e da poesia: com esclarecimentos ocasionais sobre diferentes pontos da história da arte antiga. São Paulo: Iluminuras, 1998.

MÜNSTERBERG, H. The Film: a Psychlogical Study -the Silent Photoplay in 1916. Nova York: Dover, 1970.

PERKINS, V. F. A Critical History of Early Film Theory. In: NICHOLS, B. Movies and Methods, vol. 1. Berkeley: University of California Press, 1976. p. 401-422.

PRINCE, S. True Lies: Perceptual Realism, Digital Images, and Film Theory. Film Quarterly, v. 49, n 3, p. 27-37, Spring, 1996.

PUDOVKIN, V. Métodos de tratamento do material (Montagem estrutural). In: XAVIER, I. (org.). A experiência do cinema. Rio de Janeiro: Graal/ Embrafilme, 1983. p. 57-65.

ROSEN, P. (ed.). Narrative, Apparatus, Ideology. Nova York: Columbia University Press, 1986.

SADOUL, G. História do cinema mundial - I. Lisboa: Horizonte, 1983.

SAID, E. W. Orientalismo: o Oriente como invenção do Ocidente. São Paulo: Companhia de Bolso, 2007. 
STAM, R. Introdução à teoria do cinema. Campinas: Papirus, 2003.

VERTOV, D. Nascimento do cine-olho [1924]. In: XAVIER, I. (org.). A experiência do cinema. Rio de Janeiro: Graal, 1983. p. 260-262.

Artigo recebido em 13 de outubro de 2014 e aprovado em 11 de abril de 2015. 